
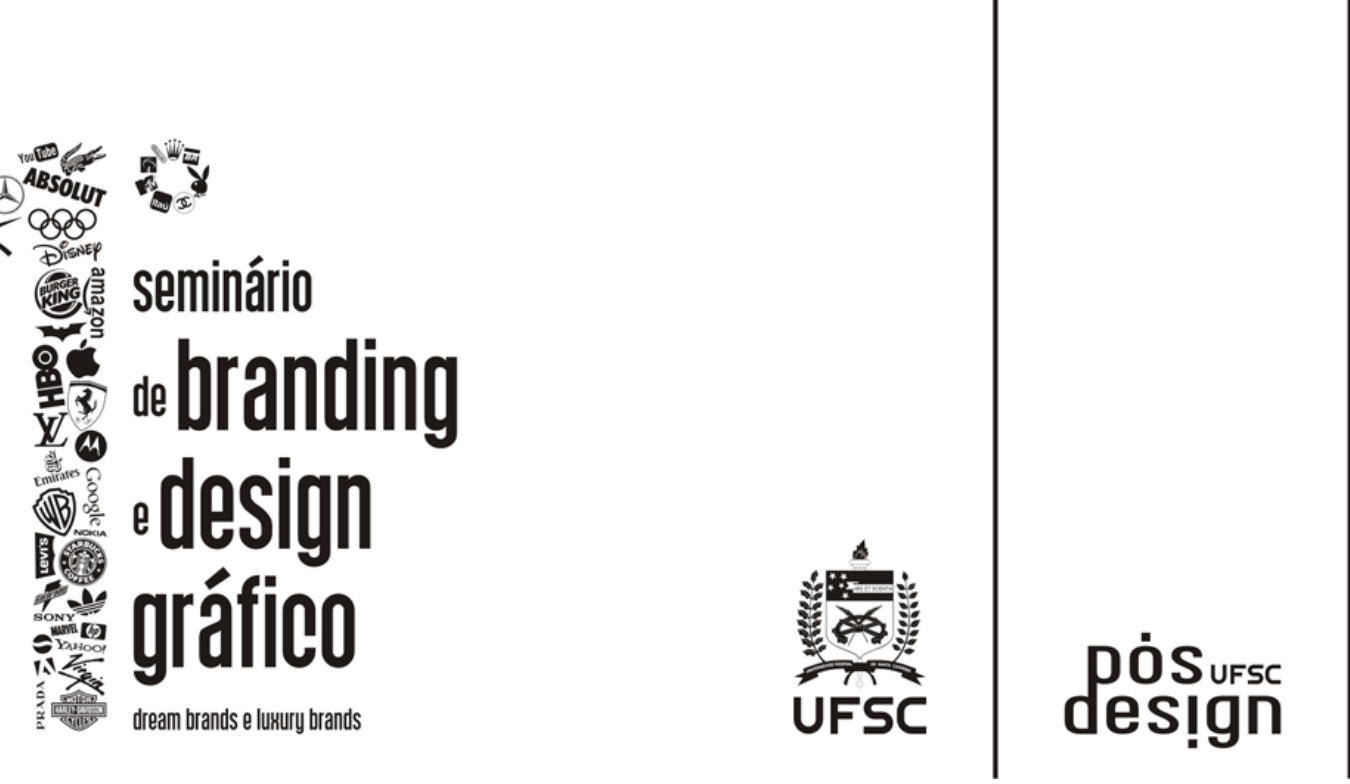

LOGO

\title{
Marcas para exportação sob a ótica do design gráfico
}

\section{Brand for exportation from the viewpoint of graphic design}

Pereira, Alice Teresinha Cybis; PhD; Universidade Federal de Santa Catarina.

Botelho , Louise; Doutoranda; Universidade Federal de Santa Catarina .

Vieira, Beatriz; MSc; Universidade Federal de Santa Catarina.

Schons , Claudine; Mestranda; Universidade Federal de Santa Catarina.

\section{Resumo}

A competitividade no mercado internacional exige das empresas um grande investimento na marca, e o design vêm se tornando um dos principais meios de agregar valor e posicionar uma marca. Nesse sentido, o trabalho pretende compreender a importância da marca no processo de exportação e que elementos são considerados importantes na construção de marcas fortes no mercado externo em relação à atuação do design gráfico. Dentro desse contexto foi realizado um estudo de caso no setor cerâmico com a empresa Portobello S/A, que foi publicada na dissertação intitulada Núcleo Virtual de Design Gráfico na Exportação: Disseminação e Gestão do Conhecimento.

Palavras Chave: marca, exportação, design gráfico.

\begin{abstract}
The international market requires large investments on branding and design is becoming one of the major means of adding value and increasing the brand of the company. This paper objective is to understand the brand in the process of export and from the viewpoint of graphic design. To archive this goal a research was develop in the ceramic industry. The research was published on the work Virtual Environment of graphic design in the exportation: knowledge dissemination and management.
\end{abstract}

Keywords: brand, exportation, graphic design. 


\section{A relação Design Gráfico e marca}

(2008) como:

Communication design is an intellectual, technical and creative activity concerned not simply with the production of images but with the analysis, organisation and methods of presentation of visual solutions to communication problems. ${ }^{1}$

Para o Centro Português de Design (1997), o designer gráfico é um especialista na criação de elementos que permitem uma identificação e diferenciação dos aspectos visuais da organização, contribuindo para a política e estratégia de comunicação da mesma. $\mathrm{O}$ design gráfico, de acordo com a ADG (2003), encontra-se segmentado em sete áreas de atuação profissional que são: Identidade corporativa, design editorial, publicações institucionais, embalagem, material promocional, design ambiental e mídia eletrônica.

O conceito de marca para Aaker (1998), refere-se os ativos e passivos ligados a ela e podem ser medidos e agrupados em cinco categorias que seriam: lealdade à marca, conhecimento do nome, qualidade percebida, associações à marca e outros ativos, como canais de distribuição, patentes, etc.

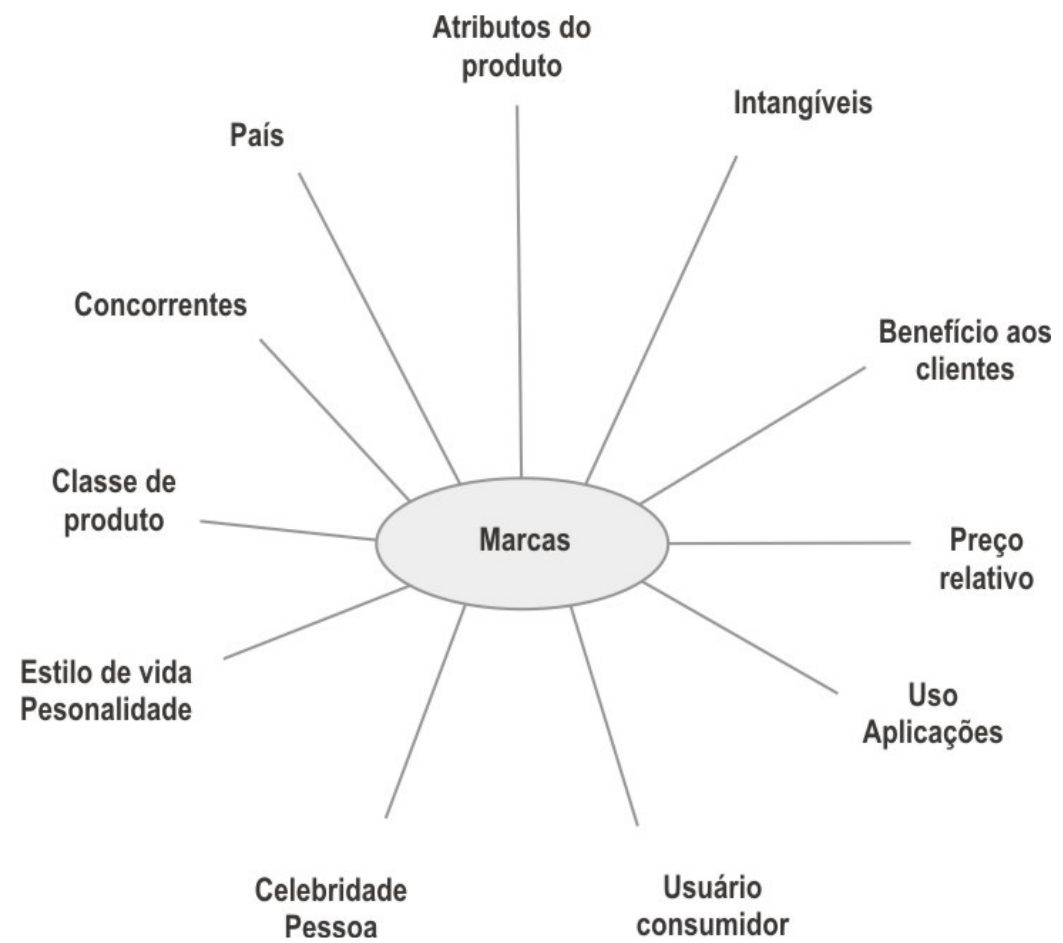

Figura 1: Associações da marca

Fonte: Figura adaptada de Aaker (1998)

\footnotetext{
1 " O design é uma atividade intelectual, técnica e criativa que consiste não simplesmente na produção de imagens, mas na análise, organização e métodos de apresentação de soluções visuais a problemas de comunicação. Informação e comunicação são as bases de uma vida independente pelo mundo nas esferas econômica, social ou cultural. A tarefa do design gráfico é proporcionar as respostas corretas aos problemas de comunicação visual de qualquer ordem em qualquer setor da sociedade" (tradução da autora).
} 
Para a exportação, a associação relacionada com o país de origem é uma das mais destacadas e pode contribuir de maneira significativa para o produto. Um país pode ser um símbolo forte se tiver ligação próxima como os produtos, materiais e capacitação.

Outra questão relevante abordada pelo autor, diz respeito à globalização das marcas, e a discussão em relação a usar o mesmo nome e símbolo gráfico em todo o mundo, ou marcas correlacionadas e adaptadas a cada país. Como argumento favorável a uma única marca globalizada o autor coloca que uma marca pode gerar vantagens substancias através do conhecimento da marca quando os consumidores viajam por diferentes países. Além disso, uma marca global pode comprar mídia mais eficientemente e proporciona freqüentemente uma associação com o país de origem.

De acordo com Pipkin (2002), a marca é um dos fatores que diferenciam a oferta da empresa de seus concorrentes, sendo um importante instrumento de agregação de valor. Para o autor, a marca é um elemento determinante para a inserção das empresas no comércio internacional, pois ela além de identificar o país, a identidade corporativa e os valores tangíveis e intangíveis da organização, torna a empresa inconfundível.

De acordo com Aaker (1998), o valor de uma marca não se concentra no nome ou símbolo gráfico, mas se esses são mudados poderão afetar todos os ativos ou passivos e mesmo serem perdidos.

Entre design gráfico e marca é mais comum e rápida a associação do design gráfico com a marca na área de identidade corporativa. Entretanto, o design gráfico participa na construção da marca em todas as suas áreas de atuação, como sugere Mozota (2003), pois a marca vai muito além do símbolo gráfico.

Mozota (2003) também afirma que a ligação entre design e imagem é mais abrangente, pois o design esta presente em todos os ativos que fazem o valor da marca: missão, posicionamento, notoriedade, expressão, promessa e qualidade.

\section{Estudo de caso Portobello S/A}

A pesquisa na empresa Portobello S/A foi desenvolvida a partir de um estudo de caso através de entrevista, com um questionário aplicado com a Coordenadora de gestão de marca da empresa, e pesquisa documental. As primeiras questões foram referentes à comunicação da empresa de forma geral, buscando identificar as diferenças na comunicação e marca para exportação, os elementos responsáveis por essa comunicação e como ela é desenvolvida na organização.

Em seguida, foram questionados aspectos relacionados à embalagem, identidade visual e marca, aos stands, aos catálogos e ao site. Esses questionamentos têm como objetivo identificar se os elementos do design gráfico estavam sendo considerados na marca para a exportação.

Essa pesquisa faz parte da dissertação de mestrado intitulada Núcleo Virtual de Design Gráfico na Exportação: Disseminação e Gestão do Conhecimento, do Programa de PósGraduação em Engenharia e Gestão do Conhecimento, da Universidade Federal de Santa Catarina. 


\section{Identidade Visual}

A marca Portobello, por uma decisão estratégica da organização, recebe o mesmo tratamento para os mercados interno e externo sendo realizadas apenas alterações indispensáveis para exportação, como as alterações no idioma.

Como a empresa exporta para distintos mercados, a penetração da marca nos mesmos também difere.

A Portobello é uma empresa que tem consciência da importância da marca e trabalha seus conceitos de maneira única no mercado interno e externo através de elementos como embalagem, identidade visual, stands, catálogos e site. Entre os veículos de emissão da marca apontados pela empresa no mercado externo, o meio onde se prestam os serviços foi considerado com menor impacto na emissão da marca.

Para a empresa é fundamental que a identidade visual apresente compatibilidade com o estilo da empresa, divulgue a visão e missão da mesma, valorize o produto e comunique associações e atributos.

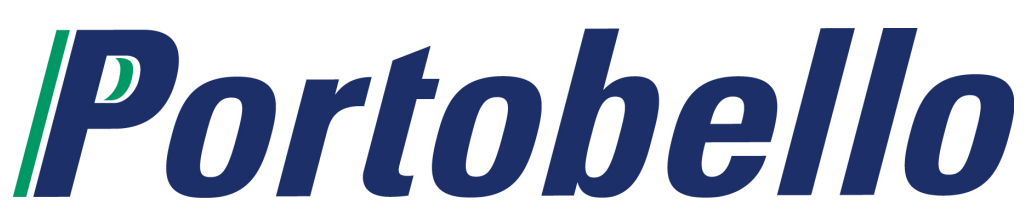

Figura 2: Marca Portobello

\section{Embalagens}

As embalagens da Portobello utilizadas no mercado externo e interno são as mesmas. Algumas pequenas alterações são necessárias para incluir informações obrigatórias determinadas pela legislação, como tamanho dos pisos cerâmicos, instruções de utilização, entre outras.

Como principal função da embalagem apontada na pesquisa encontra-se a função de acondicionar os produtos. Por não ficarem em exposição, as embalagens não tem como função principal a comunicação da marca da empresa.

A empresa considera relevantes para o desenvolvimento de embalagens destinadas ao mercado externo os fatores que dizem respeito ao meio ambiente e à legislação. Isso demonstra novamente que a embalagem não exerce influencia no momento de compra do produto, mas que pode ter importância econômica e social, ao considerar o meio ambiente.

\section{Stands}

As feiras têm grande importância para a indústria cerâmica na exportação, pois funcionam como uma vitrine para os clientes no mercado e possibilitam a realização de grandes negócios.

A Portobello participa de duas feiras no mercado externo. A primeira delas é a Cersaie, que representa o mercado mundial e a Coverings, nos Estados Unidos. Nessas feiras a empresa apresenta seus lançamentos, atendendo seus clientes.

Nesse sentido, ao apontar as principais funções das feiras, a empresa analisou com importância a participação nas feiras para a comercialização dos produtos e divulgação da marca. 


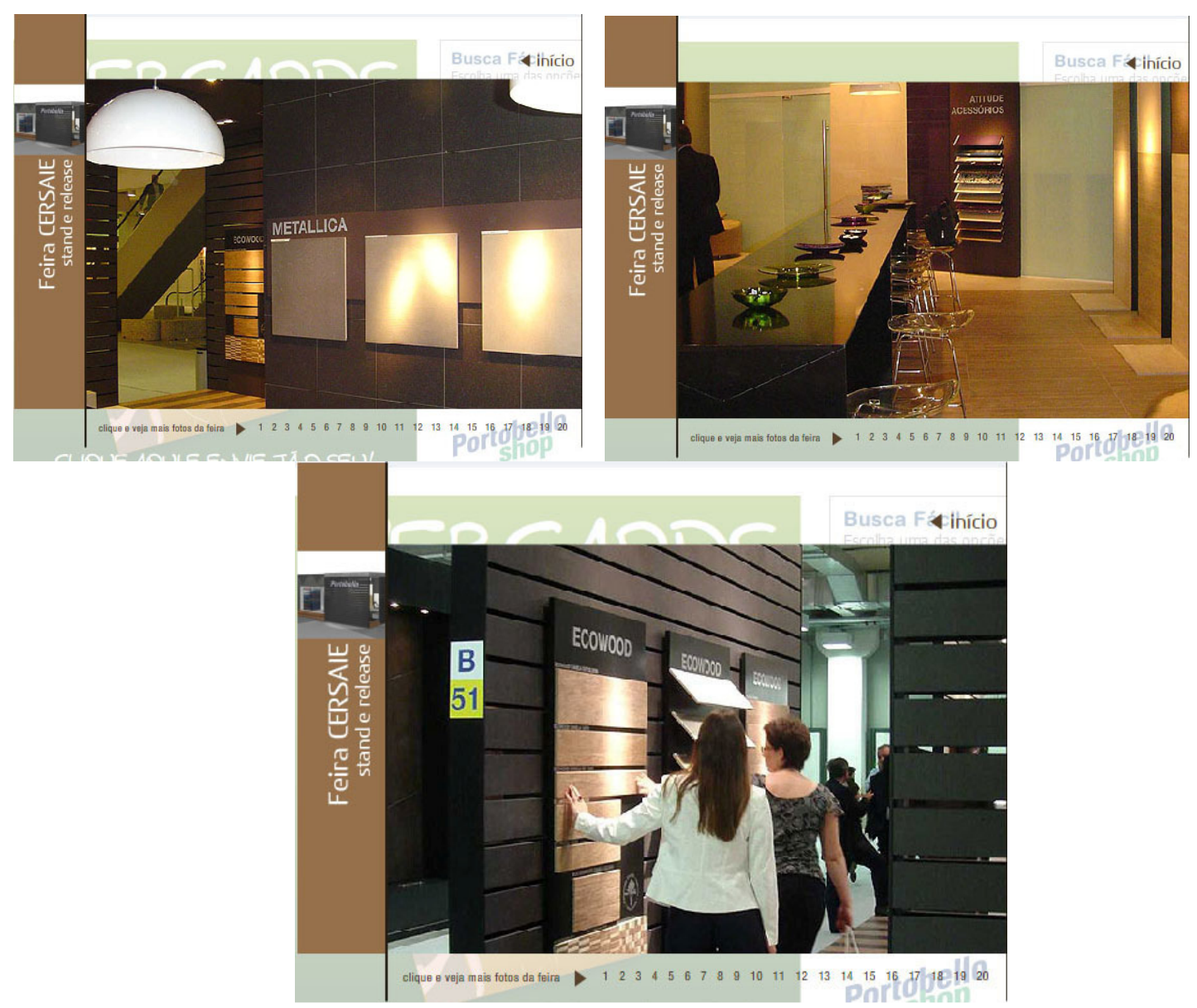

Figura 3: Stand Portobello Cersaie 2007.

\section{Catálogos}

Os catálogos têm sua importância evidenciada para a empresa já que não é possível levar para as exposições todas as linhas de produtos Portobello e os clientes podem conhecer os demais produtos através dos mesmos. É um dos meios de venda e exposição da marca e dos produtos mais importantes para a organização.

Assim como a marca, os catálogos sofrem alterações apenas no idioma para atender outros mercados. Na aplicação da pesquisa o catálogo foi apontado com importância na transmissão da comunicação do produto, da imagem corporativa da organização, nas associações e atributos da empresa. Além disso, os catálogos da empresa têm a função de transmitir responsabilidade social e ambiental da Portobello.

Os catálogos também estão todos disponíveis no site da empresa para o cliente fazer o download em versão digital e versão impressa. 

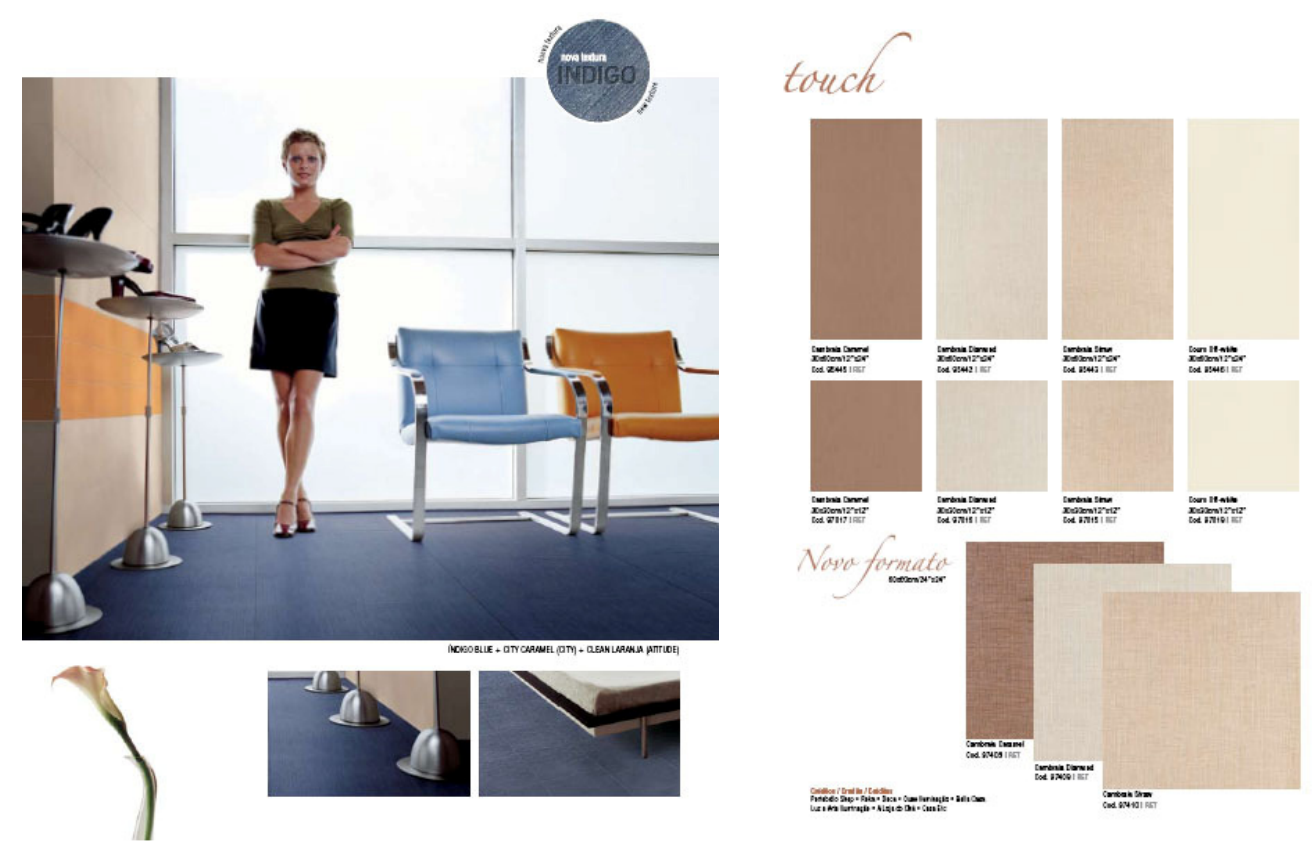

Figura 4: Catálogo Linha Touche.

\section{Site}

O site também é um importante meio de comunicação da marca e de venda para o mercado externo e, seguindo o planejamento estratégico da Portobello, o site que atende o mercado externo não apresenta nenhuma alteração além do idioma.

Como elemento de comunicação o site é apontado pela empresa com importância na comunicação dos produtos, a imagem corporativa, as associações e atributos, a responsabilidade social e ambiental, e os locais de comercialização do produto.

\section{Considerações Finais}

O desenvolvimento de marcas de expressão no mercado externo exige das empresas uma visão clara sobre o conceito de marca e tudo que envolve sua construção. Sua relação com o design gráfico se torna evidente e já vem sendo explorada positivamente pela empresa Portobello S/A, como demonstrou o estudo de caso.

A pesquisa permitiu verificar em um mercado específico, de grande expressão para o país nas exportações, o tratamento da marca para a exportação através das áreas de atuação do design, ratificando a abordagem de Mozota (2003) ao considerar todas as áreas do design gráfico responsáveis pela formação da marca e da comunicação no mercado externo.

\section{Referências}

AAKER, David A. MARCAS: Brand Equity Gerenciando o Valor de Marca. Tradução: André Andrade. São Paulo: Negócio Editora, 1998.

ABC da ADG Glossário de termos e verbetes utilizados em Design Gráfico. [1999] 
KOTLER, Philip. Administração de marketing. 5 ed. São Paulo: Atlas, 1998

MANUAL DE GESTÃo DE DESIGN. Porto: Centro Português de Design - CPD, 1997.

MOZOTA, Brigitte Borja de. Design Management: Usign Design to Build Brand Value and Corporate Innovation. New York: Allworth Press, 2003.

PIPKIN, Alex. Marketing Internacional: Uma Abordagem Estratégica. 2 Ed. São Paulo: Aduaneiras, 2002.

VIEIRA, Beatriz. Núcleo Virtual de Design Gráfico na Exportação: Disseminação e Gestão do Conhecimento. Dissertação apresentada ao Programa de Pós-graduação em Engenharia e Gestão do Conhecimento da Universidade Federal de Santa Catarina. 